\title{
Nursing satisfaction in county hospitals at the closing of health system reform round
}

\author{
Arielle Doris Kachie Tetgoum*, Zhou Lulin* \\ * Centre for Medical Insurance, Hospital Management and Health Policy Research, School of Management, Jiangsu University
}

DOI: $10.29322 /$ IJSRP.10.12.2020.p10802

http://dx.doi.org/10.29322/IJSRP.10.12.2020.p10802

\begin{abstract}
Nurses are key actors in the healthcare sector and their satisfaction is essential for patient care delivery. Assessing their professional satisfaction at the closing of a national health system reform round is therefore vital. This cross-sectional study estimated the relative importance of professional satisfaction components, evaluated the overall level of job satisfaction among nurses, and examined how the components of their perceived satisfaction vary with demographic variables. A total of 276 registered nurses from three (3) county hospitals across Jiangsu Province in China were surveyed using the Index of Work Satisfaction scale. Multiple regression models represented as structural equation models were used to estimate the effects of demographic variables on each dimension of job satisfaction. Nurses appeared to be more satisfied with their pay and professional status but dissatisfied with their task requirements and interactions. Statistically significant correlations were also found between nurses' age and years of experience and some job satisfaction components. At the end of this health system reform round, the overall level of satisfaction among nurses is still low, showing a slim contribution to the new transformations. The findings and recommendations may provide clues to help nursing managers implement informed strategies and address critical issues to increase nurses' satisfaction.
\end{abstract}

Index Terms- County hospitals, Health System, Index of Work Satisfaction, Multiple Regression, Registered Nurses.

\section{INTRODUCTION}

Job satisfaction expresses how happy a worker is, content with, or enjoys his or her job (Jun \& Jo, 2016). It has also been defined as the degree of positive affect towards a job or its components or as a pleasurable and positive emotional state resulting from the affection and the appreciation that someone has about his or her job experience (Nehrir, Ebadi, Tofighi, Karimi, \& Honarvar, 2010; Zangaro \& Soeken, 2007). P. L. Stamps (1997) understood it as the degree to which workers appreciate their jobs and have a positive or negative attitude towards them. Nursing satisfaction has been discussed a lot in the literature, but as long as the nursing profession exists, taking an interest in their well-being remains important (Chien \& Yick, 2016). Focus on nursing satisfaction traces its way long back in the '40s when Nahm, conducted the first significant study on job satisfaction among nurses at the University of Minnesota (Andrioti et al., 2017). Subsequent researches have shown that many different factors drive nurses' job satisfaction and the common ones include workload, leadership, and support (Lundmark, Nordin, Yepes-Baldó, Romeo, \& Westerberg, 2020), environmental and demographic characteristics (K. Liu et al., 2012; Tao, Guo, Liu, \& Li, 2018), communication or interaction, autonomy (Itzhaki, Ea, Ehrenfeld, \& Fitzpatrick, 2013), promotion, educational training and improvement, internal policies, insurance and safety, schedule flexibility, salary and fringe (George \& Zakkariya, 2015; Linh, Jin, Kiong, \& Fah, 2016; L.-F. Zhang et al., 2014). The role that nurses play in any given society is no longer to be demonstrated, as they provide services and help patients with their health issues around the clock (Thorne, 2020; Tourangeau, Patterson, Saari, Thomson, \& Cranley, 2017). They must then be in a perfect state of mind, without worries and anxieties to avoid costly or irreversible mistakes (Riklikien, Krušinskait, Gatautis, \& Bagdonait, 2015). It has been demonstrated that nurses' commitment, service quality, and retention are related to their job satisfaction, for when they are satisfied, they have that inner drive which prompts them to perform well and achieve personal and collective goals (Ijadi Maghsoodi, Abouhamzeh, Khalilzadeh, \& Zavadskas, 2018; Y. Wang, Chang, Fu, \& Wang, 2012; A. Zhang, Tao, Ellenbecker, \& Liu, 2013). Contrariwise, nurses whose needs are not met at the workplace tend to be low productive and could experience some level of work stress and burnout that can impoverish their health, cause them to make a poor clinical judgment, endanger their lives, and those of the patients under their care (H. Wang et al., 2020). Likewise, nursing professional dissatisfaction is generally associated with a high turnover rate leading to workers shortage in medical organizations (Riklikien et al., 2015; Yıldız, Ayhan, \& Erdoğmuş, 2009; Yun, Jie, \& Anli, 2010).

However, many studies have focused on examining the extrinsic (environmental, physical, and social) factors that can influence job satisfaction (Hayes, Douglas, \& Bonner, 2015; L.F. Zhang et al., 2014). Still, it has been argued that workers can experience different levels of job satisfaction while having the same job and working in the same environment (Spector, 2006). Some authors have attributed that difference to intrinsic factors such as personal characteristics (Curtis, 2008). Besides education, age, and years of experience have been generally associated with job satisfaction. Results from some studies on the relationship between age, years of experience, and nurses' job 
satisfaction showed a proportional relationship (Curtis, 2008; Eberhardt, Pooyan, \& Moser, 2012; Hayes et al., 2015; Hu \& Liu, 2004; Qu \& Wang, 2015; Ramoo, Abdullah, \& Piaw, 2013), while others showed a disproportional (Agho, 1993; Baggs \& Ryan, 1990) or no (Oermann, 1995) correlation between nurses' job satisfaction, age, and years of experience.

In the context of China, the health system has been repeatedly criticized for its imperfections and inequalities (La Forgia \& Yip, 2017; Yun et al., 2010; T. Zhang, Xu, Ren, Sun, \& Liu, 2017). Nurses who constitute the largest hospital workforce complained of being marginalized for the benefit of doctors. For hospitals (which are more than $60 \%$ self-funded), physicians have been considered as a source of gain through a shot up of consultations, treatments, and medications prices (La Forgia \& Yip, 2017; Milcent, 2016). With the high rate of nursing shortage due to the increasing turnover Chinese hospitals are facing now, hospital managers tend to recruit more contract-based nurses. It has been reported that contract-based nurses already represent more than $54 \%$ of nurses in Chinese hospitals (Shang et al., 2014). For instance, $59 \%$ of the participants in this study had a contract-based employment status. Moreover, they don't enjoy the same benefits (permanent contract, fixed income, health insurance, housing, and retiring allowances) as formally employed nurses and their pay and job-related benefits can vary between employers (Shang et al., 2014; Yun et al., 2010). This is a considerable threat to their retention since Chinese nurses are more and more highly educated by holding a bachelor's degree or above, which is an asset for better work positions. In our cohort, for example, $75 \%$ of nurses are university graduates. On the other side, patients also complained of the fact that healthcare services were not easily accessible and affordable (Meng, Mills, Wang, \& Han, 2019; Milcent, 2016; Yau et al., 2012; Yun et al., 2010). It was therefore necessary to find a balance between those who provide health care and those who receive care. To remedy this, the Chinese central government instructed reforms to the health system. After the first one (1996-2007) had failed, especially with the outbreak of severe acute respiratory syndrome (SARS) in 2003 which still exposed its limits, a second-round was launched in 2009. The primary purpose of this second reform round was to make the healthcare services equitable and more accessible to all and to provide people with better financial health protection by 2020 (Meng et al., 2019). The reform also advocates the old market-centered care system to be progressively replaced by a patient-centered care system, where more efforts are orientated towards providing high-quality care services (A. Zhang et al., 2013). Indeed, finding a balance between patient satisfaction and that of the medical care providers is not easy, because while the emphasis is on one, the other will feel neglected. With the rapid economic growth and development of the Chinese society, nurses in their daily professional life have to cope with a competitive and hostile environment and requirements of performances and adaptability that are increasingly tough, and above all, they must provide quality service (Guo et al., 2016). This only confirms that the nursing profession is one of the most stressful works (Chan, Lai, Ko, \& Boey, 2000). Likewise, as reported by many studies, nurses' job dissatisfaction is exacerbated by their work stress (Aiken, Clarke, Sloane, Sochalski, \& Silber, 2002; Ellenbecker, Porell, Samia, Byleckie, \& Milburn, 2008; Kalkidan, Moges
Wubie, \& Cheru Tesema, 2018; Ma, Samuels, \& Alexander, 2003; Tourangeau et al., 2017; Vander Elst et al., 2016; Yun et al., 2010). With all this in view, one wonders how Chinese nurses manage to appreciate their job, or are there still some aspects of their job that they would like to see improved, to work under better conditions that allow them to flourish and produce the expected results?

Although some studies have been devoted to nurses' job satisfaction in China (Chien \& Yick, 2016; Hu \& Liu, 2004; Tao et al., 2018; A. Zhang et al., 2013), few focused on how it varies with biographic variables such as age and year of experience. This especially with the rampant number of contract-based nurses in Chinese hospitals, who do not enjoy the same privilege as formally employed nurses. Additionally, the search for understanding the dimensions involved in the satisfaction or dissatisfaction experienced by Chinese nurses remains an ongoing area of interest for nursing managers and healthcare policymakers, because of their contribution to the stability of the health system. This study then intended to estimate the overall level of job satisfaction among Chinese nurses and determine the job components for which they are more satisfied or dissatisfied at the end of the reformation period, as a consequence of significant transformations in their workplace. Moreover, the effects of their age and clinical experience on the elements of their perceived job satisfaction were investigated. The findings of this research may provide clues to help nursing managers and policymakers implement informed strategies and address critical issues to increase nurses' satisfaction and guarantee their retention

\section{MATERIALS AND METHODS}

\subsection{Study design}

A descriptive and cross-sectional study was carried across Jiangsu province, using questionnaires to collect data. The province was divided into three main zones (northern, middle, and southern) and a purposive sampling approach was used to select three second-level hospitals, such as one in each zone. Second-level hospitals are hospitals found in small cities at the county or district level with medium size (100-500 beds), which offer comprehensive medical and healthcare services (A. Zhang et al., 2013).

\subsection{Data collection and participants}

A two-part questionnaire form was designed and sent to the selected hospitals between June-August 2019. The survey package also contained a cover letter stating the purpose of the study and assuring participants that it was voluntary and anonymous. The questionnaires were translated from English to Chinese to avoid communicational issues. Prior to the actual data collection, a pilot study was conducted in one county hospital on a sample of 10 nurses, to refine and clarify the instrument and ensure that there was no ambiguity in the questions and for the Chinese health system context. With the help of the nurses' administrators of the targeted hospitals, 300 volunteer nurses were recruited for the study. Registered nurses (RNs) who had been working for at least one full year were eligible to willfully participate in the survey. After completion of the survey 
questionnaire, nurses were supposed to seal their responses in a self-address return envelop provided in the survey package, and deposit it in the nursing office mailbox. A total of 276 responses were received from registered nurses who consented to respond and mail the questionnaire, for a response rate of $92 \%$.

\subsection{Instruments}

The survey questionnaire included a self-designed socio-demographic information questionnaire and the Index of Work Satisfaction (IWS) questionnaire. The collection of the socio-demographic information was essential to identify social and personal factors that may influence or be related to nurses' job satisfaction. The socio-demographic information consisted of gender, age, educational level, wards, clinical experience, and employment status.

The Index of Work Satisfaction (IWS) questionnaire is one of the few models providing a comprehensive framework to assess nursing job satisfaction. This model has been widely cited and used in nursing research (Ahmad, Oranye, \& Danilov, 2016; Hayes et al., 2015; Itzhaki et al., 2013; Oermann, 1995). It was developed by L. Stamps \& Piedmont (1986), based on a critical review of occupational theories in the social sciences and a series of interviews with nurses. They intended to develop a valid and reliable scale to get a quantitative estimation of the extent to which nurses appreciate their job (P. L. Stamps, 1997). The IWS is a two-part measurement tool that assesses job satisfaction based on six components. Part A of the IWS questionnaire is a paired-comparison technique which consists in calculating the impact that each component has on the overall satisfaction of the nurses surveyed. This part is made of fifteen pairings of the six components, and participants are asked to choose one component from each pair that influences the most their level of satisfaction. Part B estimates the satisfaction level for each component as well as the overall level of satisfaction. It consists of randomly ordered 44 items with positively and negatively worded statements distributed among the six component: payment (six items), autonomy (eight items), task requirements (six items), organizational policies (seven items), professional status (seven items) and interactions (ten items), subdivided into two subscales: nurse-nurse interaction (five items) and nursephysician interaction (five items).

Responses were scored on a seven-point Likert scale, going from "strongly agree" (7) to "strongly disagree" (1) for the negatively worded statements and from "strongly disagree" (1) to "strongly agree" (7) for the positively worded statements (the wording style was considered only during the analysis).

\subsection{Validity and reliability}

The IWS questionnaire content validity and construct validity have been established through factor analysis. The Cronbach's alpha of the original scale ranged from 0.82 to 0.91 , with the reliability of the overall score being 0.81 (P. L. Stamps, 1997). Multiple studies have reported that the IWS scale is valid and reliable, the Cronbach's alpha of its subscales ranging from 0.50 to 0.92 (Ahmad et al., 2016; Hayes et al., 2015; Itzhaki et al., 2013). For instance, in their study titled "Meta-analysis of the reliability and validity of Part B of the Index of Work Satisfaction across studies," the authors concluded that the IWS was reliable and valid in different settings, including community and acute care hospitals, universities, and multisite studies (Zangaro \& Soeken, 2005). In the present study, the total scale Cronbach's coefficient alpha was 0.864 , indicating a valid degree of reliability and internal consistency.

\subsection{Data analysis}

Descriptive statistical estimators were computed to examine the sample characteristics using the Statistical Package for Social Sciences (SPSS v22). The scoring procedures described in the workbook for the Index of Work Satisfaction questionnaire were applied to evaluate the perceived importance of job satisfaction components. Onyx (version 1.0-1010) was used to perform multiple regression modeling as structural equation models and estimate fitness indicators (Oertzen, Brandmaier, \& Tsang, 2015). Confidence intervals and P-values for estimating the parameters were subsequently estimated using the Laavan package (version 0.6-5) in R software (version 3.6.2). The level of significance was set to $\mathrm{P}<0.05$.

\subsection{Ethical Statements}

The Ethical Review Committee of the University approved the conduction of this study. An introductory text on the questionnaire informed the nurses about the study's purposes and clearly stated the participation conditions, the willingness, the anonymity, and other ethical aspects of the study. The Index of Work Satisfaction (IWS) questionnaire and the scoring manual originally developed by Paula Stamp were purchased from the Market Research Street, Inc., the full-service agency in charge. Consent was obtained to use the copyrighted Index of Work Satisfaction and to adapt it to the needs of the study.

\section{RESULTS}

\subsection{Demographic characteristics of registered nurses}

The demographic characteristics of the respondents are summarized in Table 1. The participants were nearly all female $(97.82 \%)$. The age range of RNs was 23 to 49 (mean age 33.43 years). Their clinical experience ranged from one to twenty years (mean 10.25 years and a standard deviation of 5.57 years). Regarding education, $75.00 \%$ graduated from university, and $25.00 \%$ had a professional diploma. The majority of participants work in the internal medicine ward $(30.00 \%)$ and the surgical department $(28.00 \%)$. As for the employment status, $59 \%$ of the nurses are contract employed, while $41 \%$ are formally employed.

\subsection{Perceived importance of job satisfaction components among RNs}

Figure 1 presents the results from part $\mathrm{A}$ of the questionnaire and shows the perceived level of importance of job satisfaction components by RNs. The component of job satisfaction ranked as the most important by the nurses was pay (weight $=3.525)$, followed by professional status (weight $=$ 3.330) and task requirements (weight $=3.113$ ). Autonomy obtained a score of 2.953, interactions a score of 2.871 , and organizational policies a score of 2.809 .

participation were also greater than the associated latent variables correlations (see Table 2). 
Table 1. Validity and reliability of the scales

\begin{tabular}{|c|c|c|c|}
\hline Variables & Category & $\begin{array}{l}\text { Total } \\
(\mathrm{N}=276)\end{array}$ & $\begin{array}{l}\text { Proportion } \\
(\%)\end{array}$ \\
\hline \multirow[t]{2}{*}{ Gender } & Male & 6 & 2.18 \\
\hline & Female & 270 & 97.82 \\
\hline \multirow{4}{*}{ Age } & $23-25$ & 40 & 14.50 \\
\hline & $26-35$ & 142 & 51.50 \\
\hline & $36-45$ & 72 & 26.10 \\
\hline & $46-49$ & 22 & 7.90 \\
\hline \multirow{3}{*}{$\begin{array}{l}\text { Clinical } \\
\text { experience }\end{array}$} & $1-5$ & 69 & 25.00 \\
\hline & $6-10$ & 80 & 29.00 \\
\hline & $11-20$ & 127 & 46.00 \\
\hline \multirow{2}{*}{ Educational level } & Professional diploma & 69 & 25.00 \\
\hline & University education & 207 & 75.00 \\
\hline \multirow{9}{*}{ Ward } & Intensive care unit & 23 & 8.41 \\
\hline & Medical ward & 83 & 30.00 \\
\hline & Obstetrics and & 31 & 11.31 \\
\hline & Gynecology ward & & \\
\hline & Operation room & 16 & 5.79 \\
\hline & $\begin{array}{l}\text { Outpatient } \\
\text { department (OPD) }\end{array}$ & 24 & 8.69 \\
\hline & Pediatrics & 11 & 4.13 \\
\hline & Surgical ward & 78 & 28.00 \\
\hline & Other & 10 & 3.67 \\
\hline \multirow{2}{*}{$\begin{array}{l}\text { Employment } \\
\text { status }\end{array}$} & Contract employed & 163 & 59.00 \\
\hline & Formally employed & 113 & 41.00 \\
\hline
\end{tabular}

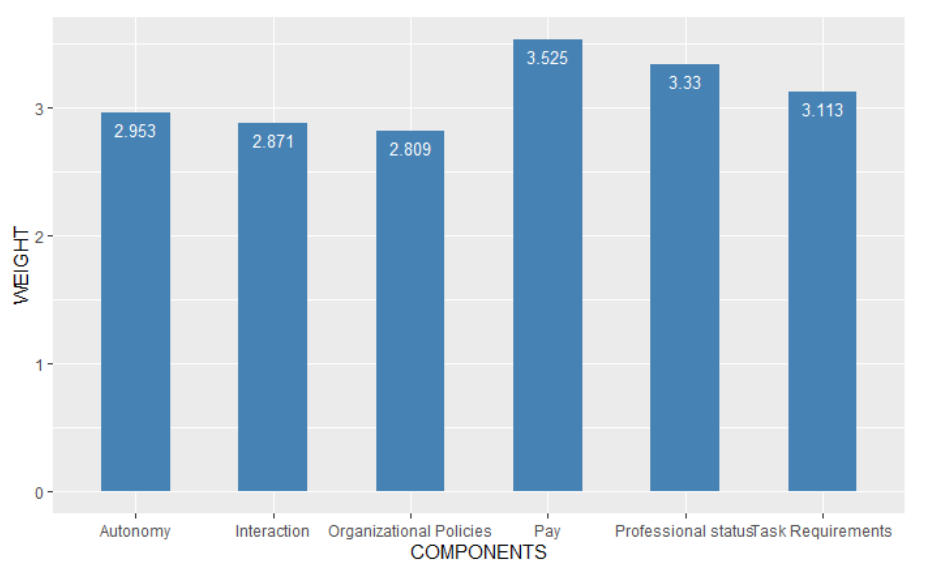

Figure 1. Relative importance of job satisfaction components among RNs

\subsection{Levels of job satisfaction components and overall job satisfaction}

The IWS components scores for part B are shown in Table 2. Chinese nurses in county hospitals were most satisfied with their pay (score $=12.126$ ) and their professional status $($ score $=11.222)$. They were the least satisfied with their task requirements (score $=7.129$ ) and their interactions (score $=$ 9.934). The organization policies component obtained a score of 10.770, while the autonomy component yielded a score of 9.893 . Overall, the Index of Work Satisfaction for all the participant nurses is low (IWS score $=10.179$ ), falling in the first quartile.
Table 3. Levels of job satisfaction components and overall IWS

\begin{tabular}{|l|l|l|l|l|}
\hline Component & $\begin{array}{l}\text { Weighting } \\
\text { Coefficient } \\
\text { (Part A) }\end{array}$ & $\begin{array}{l}\text { Component } \\
\text { Scale Score } \\
\text { (Part B) }\end{array}$ & $\begin{array}{l}\text { Component } \\
\text { Mean } \\
\text { Score } \\
\text { (Part B) }\end{array}$ & $\begin{array}{l}\text { Adjusted } \\
\text { Scores }\end{array}$ \\
\hline Pay & 3.525 & 20.420 & 3.440 & 12.126 \\
\hline Autonomy & 2.953 & 26.790 & 3.350 & 9.893 \\
\hline $\begin{array}{l}\text { Task } \\
\text { Requirements }\end{array}$ & 3.113 & 18.340 & 2.290 & 7.129 \\
\hline $\begin{array}{l}\text { Organizational } \\
\text { Policies }\end{array}$ & 2.809 & 27.640 & 3.460 & 10.770 \\
\hline $\begin{array}{l}\text { Professional } \\
\text { status }\end{array}$ & 3.330 & 26.940 & 3.370 & 11.222 \\
\hline Interaction & 2.871 & 34.570 & 3.460 & 9.934 \\
\hline \multicolumn{1}{|c|}{ Nurse-Nurse } & - & 18.500 & 3.700 & - \\
\hline Nurse-Physician & - & 16.070 & 3.200 & - \\
\hline $\begin{array}{l}\text { Total Scale } \\
\text { Score: 154.700 } \\
\text { (range: 44-308) }\end{array}$ & $\begin{array}{l}\text { Mean Scale Score: 3.228 } \\
\text { (range: 1-7) }\end{array}$ & $\begin{array}{l}\text { Overall IWS: 10.179 } \\
\text { (range: 0.9-37.1) }\end{array}$ \\
\hline \multicolumn{4}{|l|}{} & \multicolumn{2}{|l}{} \\
\hline
\end{tabular}

\subsection{Relationship between demographic characteristics and job satisfaction components}

The above results are useful for understanding what dimensions of their satisfaction the RNs value most, and the overall satisfaction level of nurses in our cohort. However, they do not tell us how demographic variables such as age and the number of years of clinical experience affect job satisfaction components. To this end, further multiple regression analyses modeled as SEM were performed to evaluate the effect of age and years of clinical experience on the perception of job satisfaction components. We experimented with six different models, and their path analysis results are shown in Figure 2. All the models produced acceptable fit to the sample data as shown by numerous goodness-of-fit statistics, and the hypotheses were examined based on standard coefficients and p-values. Fitness indicators and estimates of regression coefficients are given in Table 3 .

There were statistically significant positive relationships between age and years of experience and the perception of job satisfaction for some components, including organizational policies $(\beta=0.18, p=0.041$ for age, $\beta=0.23, p=0.001$ for experience), task requirements ( $\beta=0.28, p=0.043$ for age), and interactions $(\beta=0.47, p=0.04$ for age, $\beta=0.39, p=0.007$ for experience). Little but statistically significant reverse relationships were found between age and years of experience and the job satisfaction components pay $(\beta=-0.08, p=0.035$ for age, $\beta=-0.12, p=0.048$ for experience), and professional status $(\beta=-0.16, p=0.015$ for age, $\beta=-0.09, p=0.025$ for experience). No statistically significant relationships were found for a few paths, as can be seen in Table 3 .

The $\mathrm{R}^{2}$ obtained for the six models show that $49.6 \%$ of the variance in the perceived satisfaction with pay, $46.7 \%$ of the 
variance in the perceived satisfaction with autonomy, $45.2 \%$ of the variance in the perceived satisfaction with task requirements, $58.8 \%$ of the variance in the perceived satisfaction with organizational policies, $51 \%$ of the variance in the perceived the satisfaction with professional status, and $46.7 \%$ of the variance in perceived satisfaction with interactions, can be explained by the two demographic variables (age and years of experience)..

Model fit: $\left(\mathrm{X}^{2}=518.983 ; \mathrm{df}\right.$
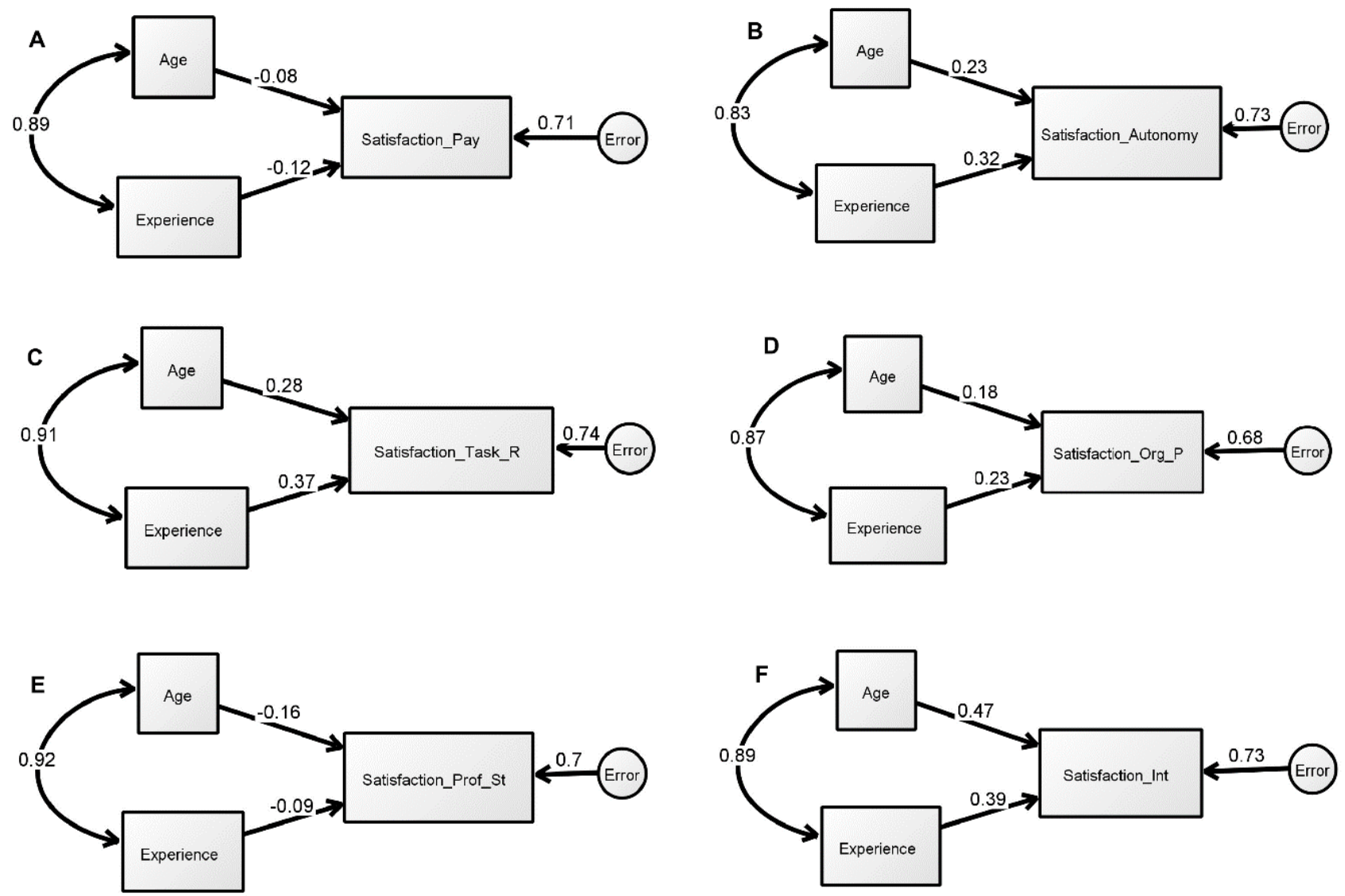

Figure 2: Multiple regression models for evaluating the effects of demographic variables on job satisfaction components

\section{DISCUSSION}

In this paper, the perceived importance of job satisfaction components was assessed as well as the overall level of job satisfaction among Chinese nurses. Moreover, the variations of the levels of job satisfaction components with the age and clinical experience of the nurses were also investigated. At the closing year of this round of the health system reform in China, the results show that the nurses perceived the new policies brought by the reform as the least contributing factor to their general satisfaction. Besides, the overall level of job satisfaction was found to be low (IWS $=10.2$ points).

Several studies aiming at evaluating the professional satisfaction of nurses in various provinces of China and conducted before or at the beginning of the current round of health system reform have also reported a low level of nursing satisfaction. For example, Lu, While, \& Louise Barriball (2007) surveyed 512 nurses in Beijing (before the ongoing reform round) and reported that $79.2 \%$ of nurses were dissatisfied with their jobs with low salaries being the leading cause. In the early beginning of the current reform, similar results were found by Ning, Zhong, Libo, \& Qiujie (2009) in Harbin, where 650 nurses from six hospitals were surveyed, and the main reasons for their dissatisfaction were a heavy workload and insufficient compensations. An investigation of 2,250 nurses from 19 general hospitals in Shanghai revealed that the majority of the nurses were dissatisfied with their jobs for several reasons including the absence of extra rewards and fringe benefits, the lack of annual leave right, and low salaries (C. Liu et al., 2012). 
Table 3: Fitness indicators and estimates of regression coefficients

\begin{tabular}{|c|c|c|c|c|c|c|c|c|}
\hline Model & SRMR & CFI & SRV & $\mathbf{R}^{2}$ & Path name & $\beta$ & $95 \% \mathrm{CI}$ & P-value \\
\hline \multirow{3}{*}{ A } & 0.001 & 1.00 & 0.50 & 0.4959 & - & - & - & - \\
\hline & & & & & Age $\rightarrow$ Pay $\dagger$ & -0.08 & {$[-0.14,-0.06]$} & $0.035^{*}$ \\
\hline & & & & & Experience $\rightarrow$ Pay $\dagger$ & -0.12 & {$[-0.16,-0.07]$} & $0.048^{*}$ \\
\hline \multirow{3}{*}{ B } & 0.001 & 0.99 & 0.53 & 0.4671 & - & - & - & - \\
\hline & & & & & Age $\rightarrow$ Autonomy $\dagger$ & 0.23 & {$[0.17,0.29]$} & 0.059 \\
\hline & & & & & Experience $\rightarrow$ Autonomy $\dagger$ & 0.32 & {$[0.21,0.34]$} & 0.065 \\
\hline \multirow{3}{*}{$\mathrm{C}$} & 0.001 & 0.98 & 0.54 & 0.4524 & - & - & - & - \\
\hline & & & & & Age $\rightarrow$ Task requirements $\dagger$ & 0.28 & {$[0.17,0.29]$} & 0.063 \\
\hline & & & & & $\begin{array}{c}\text { Experience } \rightarrow \text { Task } \\
\text { requirements } \dagger\end{array}$ & 0.37 & {$[0.29,0.40]$} & $0.043^{*}$ \\
\hline \multirow{3}{*}{$\mathrm{D}$} & 0.002 & 0.99 & 0.46 & 0.5376 & - & - & - & - \\
\hline & & & & & Age $\rightarrow$ Policies $\dagger$ & 0.18 & {$[0.10,0.21$} & $0.041 *$ \\
\hline & & & & & Experience $\rightarrow$ Policies $\dagger$ & 0.23 & {$[0.18,0.26]$} & $0.001 *$ \\
\hline \multirow{3}{*}{$\mathrm{E}$} & 0.000 & 0.99 & 0.49 & 0.51 & - & - & - & - \\
\hline & & & & & Age $\rightarrow$ Professional Status $\dagger$ & -0.16 & {$[-0.21,-0.03]$} & $0.015^{*}$ \\
\hline & & & & & $\begin{array}{l}\text { Experience } \rightarrow \text { Professional } \\
\text { Status } \dagger\end{array}$ & -0.09 & {$[-0.17,-0.07]$} & $0.025^{*}$ \\
\hline \multirow{3}{*}{$\mathrm{F}$} & 0.000 & 0.98 & 0.53 & 0.4671 & - & - & - & - \\
\hline & & & & & Age $\rightarrow$ Interactions & 0.47 & {$[0.41,0.50]$} & $0.040^{*}$ \\
\hline & & & & & Experience $\rightarrow$ Interactions & 0.39 & {$[0.31,0.42]$} & $0.007 *$ \\
\hline
\end{tabular}

SRMR: Standardized Root Mean Square Residual, CFI: Comparative Fit Index, SRV: Standardized residual covariance, R2: Coefficient of determination, $\beta$ : Standardized coefficients, $\uparrow$ : Observed level of satisfaction concerning a given component; for example, pay $\uparrow$ denotes the observed level of satisfaction concerning the component pay.

In a study conducted among 524 Chinese nurses working in five first-class tertiary hospitals in Tianjin, Yang, Liu, Chen, \& Pan (2013) reported a mean level of job satisfaction of 2.51, using the Minnesota Satisfaction Questionnaire (MSQ). While the MSQ and the IWS questionnaire used in this study operate on different scales, the overall level of job satisfaction in these two studies falls in the first quartile. A more recent study conducted on a sample of 11,337 nurses from 92 hospitals across mainland China by $\mathrm{Wu}$ et al. (2018) showed a little improvement in the nurses' level of satisfaction mainly influenced by a more conducive working environment. While nurses in the current study did not perceive the changes brought by the reform in organizational policies as very important for their satisfaction, more experienced and older nurses were found increasingly more satisfied with this component, suggesting that the new policies were somewhat effective in this respect.

Nurses in Jiangsu Province perceived pay and professional status as more important to their job satisfaction and were more satisfied with these two components. These results seem a little surprising since, in most of the above comparison studies, nurses were more dissatisfied with their pay compared to nurses surveyed in this study who seem to appreciate their salary. A possible explanation for this could be the fact that about $46 \%$ of participants have been working for more than 10 years and some of them could own a managerial position with more advantages, bonuses, and fringes benefits. Although the nurses were most satisfied with these components, however, their satisfaction with these components was found decreasing with age and professional experience. This finding disagrees with some studies early mentioned in this paper, where younger and less experienced nurses were found less satisfied compared to their older colleagues. A study by Curtis (2008) on the impact of biographical variables on job satisfaction among nurses in Dublin, Ireland, showed that nurses under 35 years old were less satisfied than nurses over the age of 36. Other studies among Chinese (Hu \& Liu, 2004), Australian (Hayes et al., 2015), and Malaysian nurses (Ramoo et al., 2013) revealed that job satisfaction and nurses' intention to leave had a significant association with age and work experience influencing that relationship; younger nurses and those with shorter work 
experience had lower satisfaction. Similar results were reported by Qu \& Wang (2015) in their study of a sample of Chinese nurses, in which those under the age of 30 and those with less than five years of clinical experience had a lower level of satisfaction associated with burnout. But this finding corroborates with those of Baggs \& Ryan (1990) and Agho (1993) who also found that job satisfaction was higher for younger nurses and those with less experience and lower for the older and the more experienced ones. A plausible explanation of this finding is that with growing age and experience, nurses might have lost their initial motivation when they saw their expectations not being met and their personal goals as related to their profession not being achieved.

The dissatisfaction of older nurses with their professional status could be explained by the fact that our experimental data sample is composed of $59 \%$ of contract-based nurses and $46 \%$ having worked for more than ten years. The preceding round of national reform has brought some changes to nursing employment in China. Formally employed nurses enjoy a position with state-guaranteed lifetime employment, opportunities for career development, and other benefits, while there is a more significant number of contract-based nurses, with limited opportunities and, job security, low wages, and benefits. Contract employed nurses tend to be more dissatisfied with their professional status and salary, compared to state-employed nurses who have more advantages (Hu \& Liu, 2004; Shang et al., 2014).

In this study, the first area of nurses' dissatisfaction was with their task requirements. However, it is some glimmer of hope here as their satisfaction with this component slightly increased with experience. Given the context of nursing shortage in China due to the high rate of turnover in recent years, nurses are assigned different, multiple responsibilities, making their workload heavier and more complex (Yau et al., 2012). The absence of a clear description of their role and tasks may result in some confusion as to what they are expected to do at any given moment or situation, which in turn may increase their level of stress.

The second component for which nurses were dissatisfied is interactions. Interactions among nurses have been shown as one of the most critical determinants of professional quality of life and job satisfaction (Bagheri et al., 2018). Conflict at the workplace has also been identified as an essential source of job dissatisfaction among nurses (Itzhaki et al., 2013; Masood \& Afsar, 2017). As a profession, nursing is associated with diverse and conflicting demands from unit managers, supervisors, physicians, the executive staff, and even patients and their families (Alshehry et al., 2019). However, when assessing their success and their achievement in the work setting, Chinese nurses highly value their interpersonal relationships with physicians (Chien \& Yick, 2016).

The third area of less satisfaction among nurses, which is close to the previously discussed, is autonomy. The lack of autonomy of nurses has already been reported in China, in comparison with Western countries. Li \& Lambert (2008) found in their investigation that Chinese nurses think they lack autonomy compared to nurses in Western countries. In China, nurses rely more on physicians for directions in their practices. Some nurses have complained of being verbally abused and not respected by patients and their relatives, and sometimes by physicians (Li \& Lambert, 2008; Yau et al., 2012). With the overall improvement of the national economy and Chinese citizens' lifestyle, the pressure on nurses by patients and their families for a better quality of care services could be higher. The same issues were found in the USA by Wright \& Khatri and Khatri (2015) in their study, where they reported that nursing practice was almost compromised due to workplace incivility between nurses and colleagues, supervisors, patients and their relatives. Independence in decision making makes nurses feel that they have the authority and the responsibility to make appropriate decisions about patient's care in any given situation. Besides, autonomy develops in them the satisfaction of being trusted by the physician and the feeling that their contribution is appreciated and that their qualification is recognized.

\subsection{Limitations}

This research had some limitations. The IWS questionnaire used in this study was initially designed to estimate the level of job satisfaction in a single organization. However, in this study, it was used to measure the level of job satisfaction across hospitals located in different cities of Jiangsu province. Thus, the results may be biased by some heterogeneities between hospitals and their surroundings. Data were collected from county hospitals that have approximately the same characteristics across the province to reduce this effect. Another limitation is that the data were collected in county hospitals only; the perceived level of job satisfaction reported by these respondents may not be representative of those of other types of hospitals or areas in Jiangsu province. More importantly, a comprehensive assessment of nursing satisfaction in China at the current time should include all hospitals and nurses across the entire nation. Though robust and more accurate, however, such an approach requires resources beyond those available for this study. This limitation might affect the generalizability of our findings. Thus, future studies could assess nursing job satisfaction and its components in other provinces of mainland China, considering the new and challenging context of the COVID-19's outbreak.

\subsection{Implications for clinical practice}

The results of this study are pointers to healthcare leaders and policymakers as to how do they need to consolidate the positive aspects of the reform and address the areas that need improvements as far as the job satisfaction, and professional well-being of nurses are concerned. The study revealed that nurses' satisfaction with pay and professional status was found decreasing with age and clinical experience. Alleviating older nurses' dissatisfaction could be done by reviewing the bonuses and other benefits related to their age and seniority. Additionally, reconsidering the clauses of the Nursing Regulation published by the Ministry of Health in 2008, emphasizing on "equal pay for equal work" could help to eliminate the disparities and inequalities among nurses, reduce the dissatisfaction with salary and benefits of contract-based nurses and strengthen the adequacy and stability of hospital nurse workforce in years to come (Shang et al., 2014).

Nurses were also found to be dissatisfied with their task requirements, interactions and complained about not having enough autonomy. Training and recruiting more nurses, 
clarifying, and rationalizing nurses' tasks and workload could be an effective way to improve nurses' satisfaction in the future. Hospital managers need to consider significantly the workplace incivility and employ proven methods for avoiding or resolving conflict among the medical staff (Hutchinson, Vickers, Jackson, $\&$ Wilkes, 2006). Working in a team of colleagues who support each other and work collectively to improve patients' care can contribute significantly to each member's satisfaction (Masood \& Afsar, 2017). Our results also suggest that nurses need more independence in their decision making at work. Hospital managers need to develop an awareness of this and create a working environment that promotes nurses' autonomy and facilitates more balanced, healthier relationships between physicians and nurses.

\section{CONCLUSION}

This study investigated the level of job satisfaction and its components among nurses in Jiangsu province, China. Our results indicate that after another round of national health system reform, despite some thin glimmers of hope, the overall level of job satisfaction of nurses is still low. Since dissatisfaction with one's job can lead to increased absenteeism, turnover, and workers shortage, recommendations have been made to improve nurses' satisfaction at the eve of another round of national health system transformations. Although there are some limitations to this study, results can contribute to the understanding of the current situation and serve as a signpost for improving the wellbeing of nurses. Nurses' professional well-being is not only beneficial for themselves, but for organizations, patients as well as communities. Ultimately, with the outbreak of the COVID-19, it has become more apparent that medical workers, especially nurses are essential to the survival of humanity (Thorne, 2020). But at the same time, it is strange to continue to talk about their lack of satisfaction and to realize that it is a profession whose image is increasingly degraded because of the sometimesunsuitable working conditions. All believe that the heroism of nurses demonstrated during this health crisis will restore the image of this profession, which will enable them to flourish better and encourage them to continue giving the best of themselves.

\section{ACKNOWLEDGMENT}

The authors are thankful to the administrators in the study hospitals who helped recruit the nurses for this study and to all the nurses who participated in the survey.

\section{REFERENCES}

Agho, A. O. (1993). The moderating effects of dispositional affectivity on relationships between job characteristics and nurses' job satisfaction. Research in Nursing AND Health, 16(6), 451-458. doi:10.1002/nur.4770160609

Ahmad, N., Oranye, N. O., \& Danilov, A. (2016). Rasch analysis of Stamps's Index of Work Satisfaction in nursing population. Nursing open, 4(1), 32-40. doi:10.1002/nop2.61

Aiken, L. H., Clarke, S. P., Sloane, D. M., Sochalski, J., \& Silber, J. H. (2002). Hospital nurse staffing and patient mortality, nurse burnout, and job dissatisfaction. Jama,

$288(16)$

$1987-1993$ 6.1987

Alshehry, A. S., Alquwez, N., Almazan, J., Namis, I. M., Moreno-Lacalle, R. C., \& Cruz, J. P. (2019). Workplace incivility and its influence on professional quality of life among nurses from multicultural background: A cross-sectional study. Journal of Clinical Nursing, 28(13-14), 2553-2564. doi:10.1111/jocn.14840

Andrioti, D., Skitsou, A., Karlsson, L. E., Pandouris, C., Krassias, A., \& Charalambous, G. (2017). Job Satisfaction of Nurses in Various Clinical Practices. International Journal of Caring Sciences, 10(1), 76.

Baggs, J. G., \& Ryan, S. A. (1990). ICU nurse-physician collaboration and nursing satisfaction. Nursing economic, 8(6), 386-392. Retrieved from http://europepmc.org/abstract/MED/2267027

Bagheri, H. M., Etemadinezhad, S., Khanjani, N., Ahmadi, O., Gholinia, H., Galeshi, M., \& Samaei, S. E. (2018). Evaluating the relationship between job stress and job satisfaction among female hospital nurses in Babol: An application of structural equation modeling. Health Promotion Perspectives, 8(2), 102-108. doi:10.15171/hpp.2018.13

Chan, K. B., Lai, G., Ko, Y. C., \& Boey, K. W. (2000). Work stress among six professional groups: the Singapore experience. Social Science AND Medicine, 50(10), 1415-1432. doi:https://doi.org/10.1016/S02779536(99)00397-4

Chien, W. T., \& Yick, S. Y. (2016). An Investigation of Nurses' Job Satisfaction in a Private Hospital and Its Correlates. The Open Nursing Journal, 10, 99-112. doi:10.2174/1874434601610010099

Curtis, E. A. (2008). The effect of biographical variables on job satisfaction among nurses. British Journal of Nursing, 17(3), 174-180. doi:10.12968/bjon.2008.17.3.28406

Eberhardt, B. J., Pooyan, A., \& Moser, S. B. (2012). Moderators of the relationship between job satisfaction and nurses' intention to quit. The International Journal of Organizational Analysis, 3(4), 394-406. doi:10.1108/eb028838

Ellenbecker, C. H., Porell, F. W., Samia, L., Byleckie, J. J., \& Milburn, M. (2008). Predictors of Home Healthcare Nurse Retention. Journal of Nursing Scholarship, 40(2), 151-160. doi:10.1111/j.15475069.2008.00220.x

Evans, J. A. (1997). Men in nursing, issues of gender segregation and hidden advantage. Journal of Advanced Nursing, 26, 226-231.

George, E., \& Zakkariya, K. A. (2015). Job related stress and job satisfaction: a comparative study among bank employees. Journal of Management Development, 34(3), 316-329. doi:10.1108/JMD-07-2013-0097

Guo, Juan, C., Jie, F., Xinling, G., Min, C., \& Yanhui, L. (2016). Structural empowerment, job stress and burnout of nurses in China. Applied Nursing Research, 31, 41-45. doi:https://doi.org/10.1016/j.apnr.2015.12.007

Hayes, B., Douglas, C., \& Bonner, A. (2015). Work environment, job satisfaction, stress and burnout among haemodialysis nurses. Journal of nursing management, 23(5), 588-598. doi:10.1111/jonm.12184

Hu, J., \& Liu, H. (2004). Job satisfaction among nurses in China. Home health care management AND practice, 17(1), 9-13. doi: $10.1177 / 1084822304268154$

Hutchinson, M., Vickers, M., Jackson, D., \& Wilkes, L. (2006). Workplace bullying in nursing: towards a more critical organisational perspective. Nursing Inquiry, 13(2), 118-126. doi:10.1111/j.14401800.2006.00314.x

Ijadi Maghsoodi, A., Abouhamzeh, G., Khalilzadeh, M., \& Zavadskas, E. K. (2018). Ranking and selecting the best performance appraisal method using the MULTIMOORA approach integrated Shannon's entropy. Frontiers of Business Research in China, 12(1), 2 doi:10.1186/s11782-017-0022-6

Itzhaki, M., Ea, E., Ehrenfeld, M., \& Fitzpatrick, J. J. (2013). Job satisfaction among immigrant nurses in Israel and the United States of America. International Nursing Review, 60(1), 122-128. doi:10.1111/j.14667657.2012.01035.x

Jun, W. H., \& Jo, M. J. (2016). Factor affecting happiness among nursing students in South Korea. Journal of Psychiatric and Mental Health Nursing, 23(6-7), 419-426. doi:10.1111/jpm.12330

Kalkidan, T., Moges Wubie, A., \& Cheru Tesema, L. (2018). Job satisfaction and associated factors among health professionals working at Western Amhara Region, Ethiopia. Health and Quality of Life Outcomes, 16(1), 65. doi:10.1186/s12955-018-0898-7

This publication is licensed under Creative Commons Attribution CC BY. 
La Forgia, G. M., \& Yip, W. (2017). China's Hospital Sector. In L. R. Burns \& G. G. E. Liu (Eds.), China's Healthcare System and Reform (pp. 219249). Cambridge University Press. doi:10.1017/9781316691113.010

Li, J., \& Lambert, V. A. (2008). Job satisfaction among intensive care nurses from the People's Republic of China. International Nursing Review, 55(1), 34-39. doi:10.1111/j.1466-7657.2007.00573.x

Linh, N. T. T., Jin, T. C., Kiong, T. P., \& Fah, B. C. Y. (2016). Work-family conflict and employee job satisfaction: A comparison of state-owned and foreign-invested enterprises in Vietnam. Journal of Asian Business Strategy, 6(4), 63-72.

Liu, C., Zhang, L., Ye, W., Zhu, J., Cao, J., Lu, X., \& Li, F. (2012). Job satisfaction and intention to leave: a questionnaire survey of hospital nurses in Shanghai of China. Journal of clinical nursing, 21(1-2), 255-263. doi:10.1111/j.1365-2702.2011.03766.x

Liu, K., You, L.-M., Chen, S.-X., Hao, Y.-T., Zhu, X.-W., Zhang, L.-F., \& Aiken, L. H. (2012). The relationship between hospital work environment and nurse outcomes in Guangdong, China: a nurse questionnaire survey. Journal of clinical nursing, 21(9-10), 14761485. doi:10.1111/j.1365-2702.2011.03991.x

Lu, H., While, A. E., \& Louise Barriball, K. (2007). A model of job satisfaction of nurses: a reflection of nurses' working lives in Mainland China. Journal of Advanced Nursing, 58(5), 468-479. doi:10.1111/j.13652648.2007.04233.x

Lundmark, R., Nordin, M., Yepes-Baldó, M., Romeo, M., \& Westerberg, K. (2020). Cold wind of change: Associations between organizational change, turnover intention, overcommitment and quality of care in Spanish and Swedish eldercare organizations. Nursing Open, $n / a(\mathrm{n} / \mathrm{a})$. doi:10.1002/nop2.615

Ma, C.-C., Samuels, M. E., \& Alexander, J. W. (2003). Factors That Influence Nurses' Job Satisfaction. Journal of Nursing Administration, 33(5), 293-299. Retrieved from https://journals.lww.com/jonajournal/Fulltext/2003/05000/Factors_Th at_Influence_Nurses_Job_Satisfaction.5.aspx

Masood, M., \& Afsar, B. (2017). Transformational leadership and innovative work behavior among nursing staff. Nursing Inquiry, 24(4), e12188. doi:10.1111/nin.12188

Meng, Q., Mills, A., Wang, L., \& Han, Q. (2019). What can we learn from China's health system reform? BMJ, 365. doi:10.1136/bmj.12349

Milcent, C. (2016). Evolution of the Health System. Inefficiency, Violence, and Digital Healthcare. China Perspectives, 2016(2016/4), 39-50. Retrieved from http://journals.openedition.org/chinaperspectives/7112

Nehrir, B., Ebadi, A., Tofighi, S., Karimi, Z. A. A., \& Honarvar, H. (2010). Relationship of job satisfaction and organizational commitment in hospital nurses. Journal of Military Medicine, 12(1). Retrieved from http://militarymedj.ir/article-1-607-en.html

Ning, S., Zhong, H., Libo, W., \& Qiujie, L. (2009). The impact of nurse empowerment on job satisfaction. Journal of advanced nursing, 65(12), 2642-2648. doi:10.1111/j.1365-2648.2009.05133.x

Oermann, M. H. (1995). Critical care nursing education at the baccalaureate level: Study of employment and job satisfaction. Heart AND Lung, 24(5), 394-398. doi:https://doi.org/10.1016/S0147-9563(05)80061-5

Oertzen, T. von, Brandmaier, A. M., \& Tsang, S. (2015). Structural Equation Modeling With Onyx. Structural Equation Modeling: A Multidisciplinary Journal, 22(1), 148-161. doi:10.1080/10705511.2014.935842

Ozdemir, A., Akansel, N., \& Tunk, G. C. (2008). Gender and career: Female and male nursing students' perceptions of male nursing role in turkey. Health Science Journal, 2(3), 169-178.

Qu, H.-Y., \& Wang, C.-M. (2015). Study on the relationships between nurses' job burnout and subjective well-being. Chinese Nursing Research, 2(2), 61-66. doi:https://doi.org/10.1016/j.cnre.2015.09.003

Ramoo, V., Abdullah, K., \& Piaw, C. (2013). The relationship between job satisfaction and intention to leave current employment among registered nurses in a teaching hospital. Journal of Clinical Nursing, 22, 3141-3152. doi:doi: 10.1111/jocn.12260

Riklikien, O., Krušinskait, D., Gatautis, R., \& Bagdonait, Ž. (2015). Nurses' Work-Related Stress, Job Satisfaction, and Intent to Leave: A Survey in Primary Health Care Centers. NERP, 5(1), 11-20.

Shang, J., You, L., Ma, C., Altares, D., Sloane, D. M., \& Aiken, L. H. (2014). Nurse employment contracts in Chinese hospitals: impact of inequitable benefit structures on nurse and patient satisfaction. Human Resources for Health, 12(1). doi:10.1186/1478-4491-12-1

Spector, P. (2006). Industrial and Organizational Psychology: Research and Practice (4th eds). John Wiley AND Sons, Inc, Hoboken, NJ.
Stamps, L., \& Piedmont, E. (1986). Nurses and Work Satisfaction: An Index for Work Satisfaction. Ann Arbor, MI: Health Administration Press Perspectives.

Stamps, P. L. (1997). Nurses and Work Satisfaction: An Index for Measurement. The American Journal of Nursing, 98(3), 16KK-16LL doi:10.5430/cns.v4n1p81

Tao, L., Guo, H., Liu, S., \& Li, J. (2018). Work stress and job satisfaction of community health nurses in Southwest China. Biomedical Research, 29(3), 510-518.

Thorne, S. (2020). Nursing in uncertain times. Nursing Inquiry, 27(2), e12352 doi:10.1111/nin.12352

Tourangeau, A. E., Patterson, E., Saari, M., Thomson, H., \& Cranley, L. (2017) Work-related factors influencing home care nurse intent to remain employed. Health Care Management Review, 42(1), 87-97. doi:10.1097/HMR.0000000000000093

Vander Elst, T., Cavents, C., Daneels, K., Johannik, K., Baillien, E., Broeck, A Van den, \& Godderis, L. (2016). Job demands resources predicting burnout and work engagement among Belgian home health care nurses: A cross-sectional study. Nursing Outlook, 64(5), 542-556. doi:10.1016/j.outlook.2016.06.004

Wang, H., Jin, Y., Wang, D., Zhao, S., Sang, X., \& Yuan, B. (2020). Job satisfaction, burnout, and turnover intention among primary care providers in rural China: results from structural equation modeling. BMC Family Practice, 21(1), 12. doi:10.1186/s12875-020-1083-8

Wang, Y., Chang, Y., Fu, J., \& Wang, L. (2012). Work-family conflict and burnout among Chinese female nurses: the mediating effect of psychological capital. BMC Public Health, 12(915). doi:0.1186/14712458-12-915

Wright, W., \& Khatri, N. (2015). Bullying among nursing staff: Relationship with psychological/behavioral responses of nurses and medical errors. Health Care Management Review, 40(2), 139-147. doi:10.1097/HMR.0000000000000015

Wu, X., Li, J., Liu, G., Liu, Y., Cao, J., \& Jia, Z. (2018). The effects of emotional labor and competency on job satisfaction in nurses of China: A nationwide cross-sectional survey. International Journal of Nursing Sciences, $\quad 5(4), 383-389$. doi:https://doi.org/10.1016/j.jpnss.2018.08.001

Yang, J., Liu, Y., Chen, Y., \& Pan, X. (2013). The effect of structural empowerment and organizational commitment on Chinese nurses' job satisfaction. Applied Nursing Research, 27. doi:10.1016/j.apnr.2013.12.001

Yau, S. Y., Xiao, X. Y., Lee, L. Y. K., Tsang, A. Y. K., Wong, S. L., \& Wong, K. F. (2012). Job stress among nurses in China. Applied Nursing Research, 25(1), doi:https://doi.org/10.1016/j.apnr.2011.07.001

Yıldız, Z., Ayhan, S., \& Erdoğmuş, Ş. (2009). The impact of nurses' motivation to work, job satisfaction, and sociodemographic characteristics on intention to quit their current job: An empirical study in Turkey. Applied Nursing Research, 22(2), 113-118. doi:https://doi.org/10.1016/j.apnr.2007.06.002

Yun, H., Jie, S., \& Anli, J. (2010). Nursing shortage in China: State, causes, and $\begin{array}{llll}\text { strategy. Nursing Outlook, } & 58(3), & 122-128\end{array}$ doi:https://doi.org/10.1016/j.outlook.2009.12.002

Zangaro, G. A., \& Soeken, K. L. (2005). Meta-analysis of the reliability and validity of Part B of the Index of Work Satisfaction across studies. Journal of nursing measurement, 13(1), 7 doi: $10.1891 / 106137405780954514$

Zangaro, G. A., \& Soeken, K. L. (2007). A meta-analysis of studies of nurses' job satisfaction. Research in Nursing \& Health, 30(4), 445-458. doi:10.1002/nur.20202

Zhang, A., Tao, H., Ellenbecker, C. H., \& Liu, X. (2013). Job satisfaction in mainland China: comparing critical care nurses and general ward nurses. Journal of advanced nursing, 69(8), 1725-1736. doi:10.1111/jan.12033

Zhang, L.-F., You, L.-M., Liu, K., Zheng, J., Fang, J.-B., Lu, M.-M., Lv, A.-L., et al. (2014). The association of Chinese hospital work environment with nurse burnout, job satisfaction, and intention to leave. Nursing outlook, 62(2) doi:https://doi.org/10.1016/j.outlook.2013.10.010

Zhang, T., Xu, Y., Ren, J., Sun, L., \& Liu, C. (2017). Inequality in the distribution of health resources and health services in China: hospitals versus primary care institutions. International Journal for Equity in Health, 16(42). doi:10.1186/s12939-017-0543-9 


\section{AUTHORS}

First Author - Arielle Doris Kachie Tetgoum, Ph.D Candidate, Jiangsu University, China, 5103170237@stmail.ujs.edu.cn Second Author - Zhou Lulin, Ph.D, Jiangsu University, China, zll62@ujs.edu.cn
Correspondence Author - Arielle Doris Kachie Tetgoum, Centre for Medical Insurance, Hospital Management and Health Policy Research, School of Management, Jiangsu University, No. 301 Xuefu Road, Zhenjiang 212013, Jiangsu, P.R. China email: 5103170237@stmail.ujs.edu.cn 